\title{
Effect of type and timing of oil supplements to sows during pregnancy on the growth performance and endocrine profile of low and normal birth weight offspring
}

\author{
John Laws, Jennie C. Litten, Alison Laws, Ian J. Lean, Peter F. Dodds and Lynne Clarke* \\ Department of Agricultural Sciences, Faculty of Natural Sciences, Imperial College London, Wye, Ashford, Kent TN25 5AH, UK
}

(Received 24 September 2007 - Revised 1 April 2008 - Accepted 7 April 2008 - First published online 2 September 2008)

Eighty-eight multiparous sows were used to evaluate whether type and timing of oil supplementation during gestation influences the incidence of low birth weight (LBW). Sows were allocated (eight per treatment) commercial sow pellets ( $3 \mathrm{~kg} / \mathrm{d}$; control diet) or an experimental diet consisting of control diet plus $10 \%$ extra energy in the form of excess pellets, palm oil, olive oil (OO), sunflower oil (SO) or fish oil; experimental diets were fed during either the first half (G1) or second half (G2) of gestation. Growth performance and endocrine profile of LBW $(<1.09 \mathrm{~kg})$ and normal birth weight (NBW; 1.46-1.64 kg) offspring were compared. Maternal dietary supplementation altered the distribution curve for piglet birth weight. SOG1 sows had a greater proportion of LBW piglets $(P<0.05)$, whilst it was reduced in the OOG1 group $(P<0 \cdot 05)$. Growth rate of LBW piglets was lower compared with their NBW siblings $(P<0.05)$ when dietary supplementation was offered in $\mathrm{G} 2$ but were similar for G1. At birth, LBW offspring of supplemented animals possessed more fat compared with the control group $(P<0 \cdot 05)$; LBW offspring of control animals exhibited a more rapid decline in fat free mass $/ \mathrm{kg}$ prior to weaning. Plasma metabolites and insulin concentrations were influenced by maternal diet and birth weight. In conclusion, maternal dietary supplementation altered the distribution of piglet birth weights and improved the energy status of LBW piglets. Supplementation with MUFA during G1 reduced the incidence of LBW, whereas PUFA had the reverse effect.

Birth weight: Piglet growth: Body composition: Oil

In the UK, mortality of live born piglets is approximately $11 \%{ }^{(1)}$ with over $50 \%$ of deaths occurring within $3 \mathrm{~d}$ of birth $^{(2,3)}$. Many factors influence piglet mortality ${ }^{(4)}$, but one of the main causes of mortality is cold stress due to lack of energy reserves at birth $^{(4-7)}$.

There is a plethora of data demonstrating that fat supplementation of sow diets during late gestation increases liver glycogen and body fat reserves in their offspring at birth $^{(8-10)}$. Furthermore, it is well established that fat supplementation of sow diets during late gestation improves the growth performance and survival of their offspring ${ }^{(11-13)}$; this improvement is most pronounced in low birth weight (LBW) piglets ${ }^{(14-17)}$. There is also some evidence to suggest that the fatty acid profile of the supplement is of importance; Jean \& Chiang ${ }^{(18)}$, for example, observed that medium-chain TAG and coconut oil were more effective than soya oil at reducing piglet morbidity and mortality.

Substantial evidence now exists to support Barker's fetal origins hypothesis, which suggests that fetal undernutrition is associated with an altered fetal and placental endocrine environment, thereby linking fetal undernutrition with abnormal organ structure, function and disease in later life ${ }^{(19,20)}$. Fetal nutrition is dependent upon the transfer of nutrients across the placenta. Manipulation of placental development by maternal nutrition, during early-mid-gestation, is therefore likely to have direct consequences for fetal nutrition and development. Our previous work ${ }^{(21)}$ suggests that energy supplementation and the fatty acid profile of the maternal diet during the first half of gestation influence the growth and development of piglets both in utero and during postnatal life. Since LBW has previously been linked to placental insufficiency ${ }^{(22)}$ and placental development occurs during the first half of gestation ${ }^{(23,24)}$, it seems probable that the maternal diet during early gestation will also have some influence upon the incidence of LBW. It was the aim of the present study to determine the consequences of altering the fatty acid profile of a $10 \%$ dietary supplement, offered either during the first half or second half of pregnancy on the incidence of LBW piglets and their subsequent growth and endocrine profiles.

\section{Methods \\ Animals and diets}

All animals used in these studies were maintained at the Pig Research and Development Unit, Imperial College London. Experimental procedures were carried out according to the regulations of the Animals (Scientific Procedures) Act, 1986

Abbreviations: DE, digestible energy; FFM, fat-free mass; G1 and G2, first and second half of gestation, respectively, used for the experimental diets; IGF, insulinlike growth factor; LBW, low birth weight; NBW, normal birth weight.

* Corresponding author: Lynne Clarke, fax +44 207594 2640, email lynne.clark@imperial.ac.uk 
and were licensed by the Home Office (UK). At all stages of life, animals were kept within the guidelines set out by the Department for Environment, Food and Rural Affairs ${ }^{(25)}$.

Initially birth weight data for the litters of a control population of fifty multiparous sows, of the same genetic line as those used in this experiment, were pooled and a probability plot of their weight constructed in MINITAB (Fig. 1). Piglets with a birth weight under the 10th percentile for the population were considered to be of LBW, while those between the 40th and 60th percentiles were considered to be of normal birth weight (NBW). In the control population, the LBW animals weighed less than $1.09 \mathrm{~kg}$ and NBW animals were between $1.46 \mathrm{~kg}$ and $1.64 \mathrm{~kg}$. These weight boundaries were used to classify LBW and NBW piglets within the litters of experimental animals at birth.

Eighty-eight sows of a commercial genotype (25\% Meishan; $12.5 \%$ Duroc; $62.5 \%$ Large White $\times$ Landrace) were entered into the study after weaning and prior to service. Sows were categorized by parity before being randomly assigned to one of eleven dietary treatment groups, to ensure that parity was balanced across treatments. All sows were artificially inseminated with pooled Large White semen (P17 2006; JSR Genetics, Southburn, Driffield, East Yorkshire, UK). The control diet consisted of the standard diet $(3 \mathrm{~kg} / \mathrm{d})$ ( $\mathrm{ABN} \mathrm{HE}$ sow pellets; $13.1 \mathrm{MJ} / \mathrm{kg}$ metabolizable energy; $12.7 \%$ protein; $4.5 \%$ fat; ABN, Peterborough, Cambridgeshire, UK), and

(a)

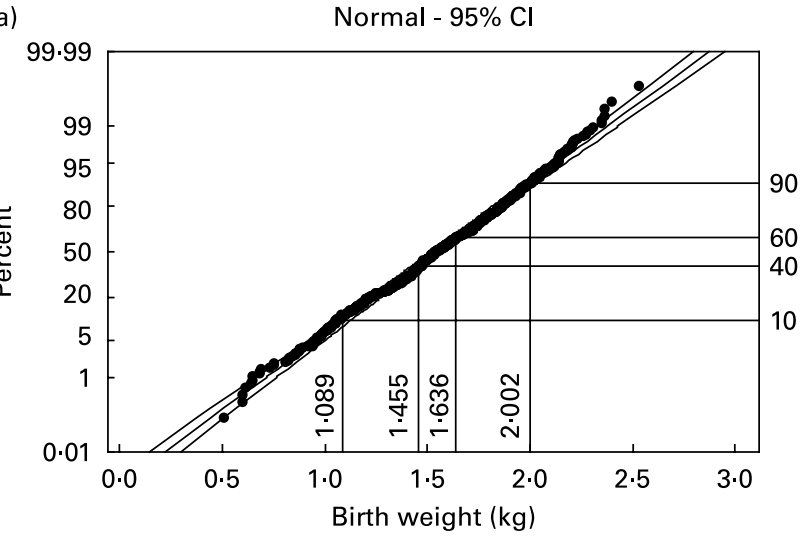

(b)

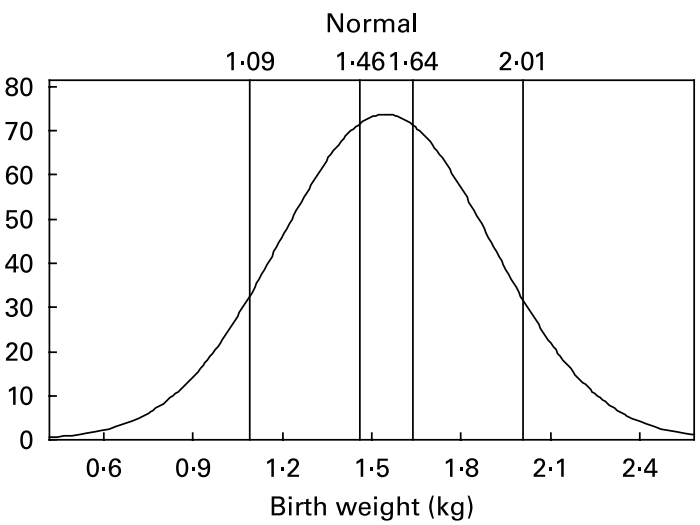

Fig. 1. (a) Probability plot and (b) distribution curve of piglet birth weight in a control population (659 piglets) born to fifty multiparous sows of a commercial genotype (25\% Meishan; $12.5 \%$ Duroc; $62.5 \%$ Large White $\times$ Landrace). Mean 1.54 (SD 0.36) kg. was fed throughout gestation. Experimental diets were as the control ration plus $10 \%(3.93 \mathrm{MJ} / \mathrm{d})$ extra energy derived from either: (i) excess pellets (E); (ii) palm oil (PO); (iii) olive oil (OO); (iv) sunflower oil (SO); (v) fish (salmon) oil (FO). Experimental diets were fed during either the first half (G1; from days 0 to 60 of gestation) or second half (G2; from day 60 of gestation until term at approximately day 115 of gestation). During the period when supplemented diets were not received, experimental sows were offered the standard diet $(3 \mathrm{~kg} / \mathrm{d})$ as for the control group. Fatty acid profiles of the diets were determined by GLC and can be seen in Table 1. All diets, with the exception of the control ration, were isoenergetic. Between farrowing and weaning (21-28d post partum) sows were offered a standard lactation ration (6-9 kg) (ABN supreme lactation pellets; $14.1 \mathrm{MJ} / \mathrm{kg}$ metabolizable energy; $18 \%$ protein; $7.2 \%$ oil; ABN). Piglets had ad libitum access to creep feed (Primary Select; $17.35 \mathrm{MJ} / \mathrm{kg}$ digestible energy (DE), 23.5\% protein; Primary Diets Ltd., Melmerby, Ripon, North Yorkshire, UK) from day 14 of life.

All piglets were weaned at 21-28d, provided they weighed more than $6.5 \mathrm{~kg}$. Piglets that failed to reach $6.5 \mathrm{~kg}$ by this age were fostered on to another sow for a further 1-2 weeks. Post-weaning management of all pigs was according to the standard procedures of the College Pig Unit. Maximum group sizes were thirty animals per pen (total area $5.45 \mathrm{~m}^{2}$; minimum area per pig $0.18 \mathrm{~m}^{2}$ ); animals were grouped according to sex and weight and food was available ad libitum throughout post weaning (Primary Benefit; $15.6 \mathrm{MJ} / \mathrm{kg} \mathrm{DE}$, $22.8 \%$ protein; Primary Diets Ltd.), growing (Delatwean 10 salocin pellets; $15 \mathrm{MJ} / \mathrm{kg} \mathrm{DE} ; 20.9 \%$ protein; $\mathrm{ABN}$ ) and fattening (Deltagrow 25 salocin pellets; $14 \mathrm{MJ} / \mathrm{kg} \mathrm{DE} ; 17.8 \%$ protein; $\mathrm{ABN}$ ) periods.

\section{Piglet growth and composition}

Piglet growth performance was observed throughout the neonatal period; body weight, crown to rump length and body composition using a total body electrical conductivity analysing system (TOBEC, Model-SA3000 EMSCAN/TOBEC, SA3203; EM-Scan Inc., Springfield, IL, USA) were recorded on days $0,7,14$ and 21 of life. Piglet growth rate was calculated by regression analysis of piglet weight against time. Piglet fat free mass (FFM) per $\mathrm{kg}$ was calculated using the equation, shown later, as suggested in the TOBEC manufacturer's instructions.

$\mathrm{FFM}($ arbitrary units $)=\frac{\sqrt{\text { TOBECreading } \times \text { Crowntorumplength }}}{\text { Pigletweight }(\mathrm{kg})}$

At commercial end-point (80 (SE 5) kg) back fat and eye muscle depth were measured, at the $\mathrm{P} 2$ position, using ultrasound (Aloka-echo camera 550-500; Aloka Ltd., Osaka, Japan).

\section{Milk intake}

Individual piglet milk intake was assessed using an adaptation of the weigh-suckle-weigh method, described by Sinclair et al. ${ }^{(26)}$. Intake was assessed on days 3, 7, 14 and 21 of lactation. The first recording of milk intake was conducted on day 3 to ensure that we were not measuring colostral yield. Natural suckling was allowed, and the inter-suckling interval recorded. 
Table 1. The fatty acid composition of diets ${ }^{*}$

(Mean percentages of total lipid fraction)

\begin{tabular}{|c|c|c|c|c|c|}
\hline \multirow[b]{2}{*}{ Fatty acid } & \multicolumn{5}{|c|}{$\mathrm{g} / 100 \mathrm{~g}$ fatty acids } \\
\hline & Control/excess diet & Palm oil diet & Olive oil diet & Sunflower oil diet & Fish oil diet \\
\hline $14: 0$ & 0.53 & 0.8 & 0.43 & 0.29 & $2 \cdot 35$ \\
\hline $15: 0$ & 0.09 & 0.15 & 0.06 & 0.08 & 0.27 \\
\hline $16: 0$ & $18 \cdot 24$ & 28.07 & $16 \cdot 37$ & 11.81 & $16 \cdot 33$ \\
\hline $16: 1 n-7$ & 0.32 & 0.40 & 0.77 & 0.31 & $3 \cdot 28$ \\
\hline $17: 1$ & 0.08 & 0.08 & 0.13 & 0.07 & 0.29 \\
\hline $18: 0$ & 3.14 & 3.73 & 3.11 & 3.45 & $2 \cdot 79$ \\
\hline $18: 1 n-9$ & 19.98 & $29 \cdot 35$ & 46.59 & 21.64 & 19.50 \\
\hline $18: 2 n-6$ & $50 \cdot 33$ & 33.46 & $27 \cdot 17$ & 57.97 & $32 \cdot 24$ \\
\hline $18: 3 n-3$ & 4.76 & 2.93 & $2 \cdot 3$ & 2.93 & 3.48 \\
\hline $20: 1 n-9$ & 0.66 & 0.46 & 0.67 & 0.40 & $4 \cdot 12$ \\
\hline $20: 2 n-6$ & 0.25 & 0.08 & 0.015 & ND & ND \\
\hline $20: 3 n-3$ & 0.04 & ND & 0.03 & ND & 0.09 \\
\hline $20: 4 n-6$ & 0.00 & 0.00 & 0.02 & 0.00 & 0.25 \\
\hline $20: 5 n-3$ & 0.35 & 0.12 & 1.00 & 0.17 & $4 \cdot 34$ \\
\hline $22: 0$ & 0.65 & 0.15 & 0.46 & 0.54 & 0.35 \\
\hline $22: 1 n-9$ & 0.38 & 0.13 & 0.25 & 0.15 & $4 \cdot 16$ \\
\hline $22: 4 n-6$ & ND & ND & ND & ND & 0.07 \\
\hline $22: 3 n-3$ & ND & ND & ND & ND & 0.13 \\
\hline $22: 5 n-3$ & 0.00 & $0 \cdot 10$ & 0.14 & 0.13 & 1.22 \\
\hline $22: 6 n-3$ & 0.21 & 0.00 & 0.35 & 0.07 & 4.73 \\
\hline
\end{tabular}

ND, none detected

*For details of diets and procedures, see Methods.

Piglets were observed throughout and weighed individually before and after four consecutive sucklings. Urination and defecation by piglets during this period was also recorded. The following equation was used to estimate milk intake per suckling:

$$
\text { Milk yield }(\mathrm{kg})=W+U+D+M,
$$

where $W$, piglet weight gain $(\mathrm{kg})$; $U$, weight loss due to urination; $D$, weight loss due to defecation; $M$, metabolic weight loss. Weight loss due to urination was calculated using the equation described by Klaver et al. ${ }^{(27)}$ :

$$
\text { Weight loss }=\left(U\left(2 \cdot 9 W^{0.75}+18 \cdot 7\right)\right),
$$

where $U$, number of urinations; $W^{0.75}$, piglet metabolic weight.

A $10 \mathrm{~g}$ loss was allowed per defecation ${ }^{(26)}$. An estimate of metabolic loss was calculated using the equation described by Noblet \& Etienne ${ }^{(28)}$.

$$
\text { Weight loss }(\mathrm{mg})=60 \text { per } \mathrm{kg} \text { live weight per min. }
$$

\section{Blood sampling}

Blood samples were obtained from the piglets on days 3 and 21 of life. Blood was put into an EDTA tube and immediately placed on ice and after centrifugation at $1600 \mathrm{~g}$ the plasma was removed and stored at $-20^{\circ} \mathrm{C}$ until further analysis. Plasma concentrations of leptin (Biogenesis XL-85; Biogenesis Ltd., Poole, Dorset, UK), insulin (ICN 07-260102; ICN Pharmaceuticals, New York, USA), insulin-like growth factor (IGF)-1; DSL-2800; Diagnostic Systems Laboratories Inc., Webster, Tx, USA) and thyroid hormones (triiodothyronine (ICN 07B74102; ICN Pharmaceuticals) and thyroxine (ICN 06B256447; ICN Pharmaceuticals) were determined by RIA using commercially available kits. Glucose (GL 366; Randox Laboratories Ltd., Crumlin, Antrim, UK), TAG (TR 148; Randox Laboratories Ltd.) and NEFA (944-75 409; Wako Chemicals GmbH, Neuss, Germany) were measured enzymatically. A reference sample was included in every assay and the intra- and inter-assay $\mathrm{CV}$ were below 5 and $10 \%$ respectively.

\section{Statistical analysis}

One of the control sows became unwell shortly after farrowing and her piglets had to be weaned early. All data from this animal and her offspring were removed prior to analysis. Data were analysed with general linear model ANOVA using MINITAB version 13.1 computer software (Minitab Ltd., Coventry, UK). The main effect included in the model was dietary treatment; parity was included as a covariate. Data were adjusted for litter size or number of piglets reared as appropriate. When treatment effects were significantly different, pair-wise comparisons of means were conducted using Tukey's test. Probability values of less than 0.05 were considered to be statistically significant.

Individual piglet growth rate was calculated by regression analysis of piglet weight against time. Analysis was conducted for two separate periods: (i) birth to weaning; (ii) over the lifetime of the pig up to commercial end-point. The slope of the line gave a measure of their growth rate $(\mathrm{kg} / \mathrm{d})$.

\section{Results}

After adjustment for both parity and litter size, the type and timing of maternal supplementation influenced the incidence of LBW piglets $(P<0 \cdot 05$; Table 2$)$. The percentage of piglets born alive that could be categorized as LBW was highest in the 
Table 2. Effect of timing and type of maternal supplement on the incidence of low birth weight (LBW; $<1.09 \mathrm{~kg})$ and normal birth weight (NBW; $1.46-$ $1.64 \mathrm{~kg}$ ) piglets

(Least squares means with their standard errors)

\begin{tabular}{|c|c|c|c|c|c|c|c|c|c|c|}
\hline & & \multirow[b]{2}{*}{ Total LBW } & \multirow[b]{2}{*}{ Total NBW } & \multirow[b]{2}{*}{ Total piglets } & \multirow[b]{2}{*}{$\%$ LBW } & \multirow[b]{2}{*}{$\%$ NBW } & \multicolumn{2}{|c|}{$\begin{array}{l}\text { Adjusted \% } \\
\text { LBW } \neq\end{array}$} & \multicolumn{2}{|c|}{$\begin{array}{l}\text { Adjusted \% } \\
\text { NBW } \neq\end{array}$} \\
\hline & & & & & & & Mean & SEM & Mean & SEM \\
\hline & Control & 6 & 33 & 72 & 8 & 46 & 9 & 4 & 28 & 5 \\
\hline \multirow[t]{5}{*}{$\mathrm{G} 1(0-60 \mathrm{~d})$} & $\mathrm{E}$ & 12 & 44 & 107 & 11 & 41 & 11 & 3 & 20 & 4 \\
\hline & $\mathrm{PO}$ & 19 & 40 & 120 & 16 & 33 & 13 & 3 & 23 & 4 \\
\hline & OO & 4 & 39 & 91 & 4 & 43 & $5^{*}$ & 3 & 23 & 4 \\
\hline & so & 8 & 32 & 95 & 8 & 34 & $20^{*}$ & 3 & 16 & 4 \\
\hline & FO & 18 & 45 & 102 & 18 & 44 & 12 & 3 & 22 & 4 \\
\hline \multirow[t]{5}{*}{ G2 (60 d-term) } & $E$ & 12 & 37 & 102 & 12 & 36 & 9 & 3 & 21 & 4 \\
\hline & PO & 10 & 47 & 93 & 11 & 51 & 10 & 3 & 25 & 4 \\
\hline & OO & 9 & 40 & 87 & 10 & 46 & 17 & 3 & 27 & 5 \\
\hline & so & 13 & 35 & 95 & 14 & 37 & 16 & 3 & 22 & 4 \\
\hline & FO & 15 & 48 & 96 & 16 & 50 & 10 & 4 & 20 & 4 \\
\hline
\end{tabular}

E, excess; PO, palm oil; OO, olive oil; SO, sunflower oil; FO, fish oil; G1, first half of gestation; G2, second half of gestation.

${ }^{\star}$ Mean values were significantly different $(P<0.05)$.

†For details of diets and procedures, see Methods.

$\ddagger$ Data for number of piglets born alive were analysed in Minitab using ANOVA general linear model (parity $(P<0.05)$ and litter size $(P<0.001)$ were analysed as covariates).

litters of SOG1 sows, and lowest in those of OOG1 animals $(P<0 \cdot 05$; Table 2$)$. The incidence of NBW piglets was similar irrespective of sow parity, litter size and type or timing of maternal supplementation (Table 2).

Comparison of the distribution curve for piglet birth weights, within each treatment, gives some insight into the effect of the different dietary supplements (Fig. 2). The OOG1 diet resulted in a shift of the distribution curve to the right (i.e. an increase in the average piglet birth weight, while deviation from the mean was similar to that observed in other groups), meaning that fewer than $10 \%$ of the OOG1 piglets fell below the 10th percentile weight $(1.09 \mathrm{~kg})$ derived from the control population. In contrast, the SOG1 diet resulted in a shift of the distribution curve to the left and a slight skewing towards the left (i.e. a slight decrease in average birth weight, with a tendency for an increased proportion of LBW piglets), meaning that more than $10 \%$ of piglets fell below the 10th percentile weight $(1.09 \mathrm{~kg})$ for the control population. Interestingly, the POG1 diet appeared to result in a shift of the distribution curve to the left and to result in a wider shallower curve (i.e. a slight decrease in average birth weight and a greater proportion of piglets at either end of the weight range); these differences appear to be largely attributable to the increased litter size observed on this treatment.

G2 supplementation with $\mathrm{OO}$ or SO diets resulted in a shift of the distribution curve for piglet birth weight to the left (i.e. a decrease in the average birth weight). In contrast supplementation with the E diet during G2 resulted in a shift of the peak to the right as a result of a skewing towards heavier piglets (i.e. an increase in the average birth weight of piglets, with a more gradual decline in frequency at the heavier end of the range).

By $21 \mathrm{~d}$ of age, after correction for maternal parity and litter size, the surviving LBW offspring of FOG1 and FOG2 sows were still lighter than their NBW siblings $(P<0.05$; Table 3). A similar pattern was observed in the weights of the offspring of SOG2 sows $(P<0.05$; Table 3$)$ on day 21 of life. At $21 \mathrm{~d}$ of age the offspring of SOG2 sows were lighter than those of FOG1 or EG2 animals $(P<0.001$ and $P<0.05$ respectively; Table 3).
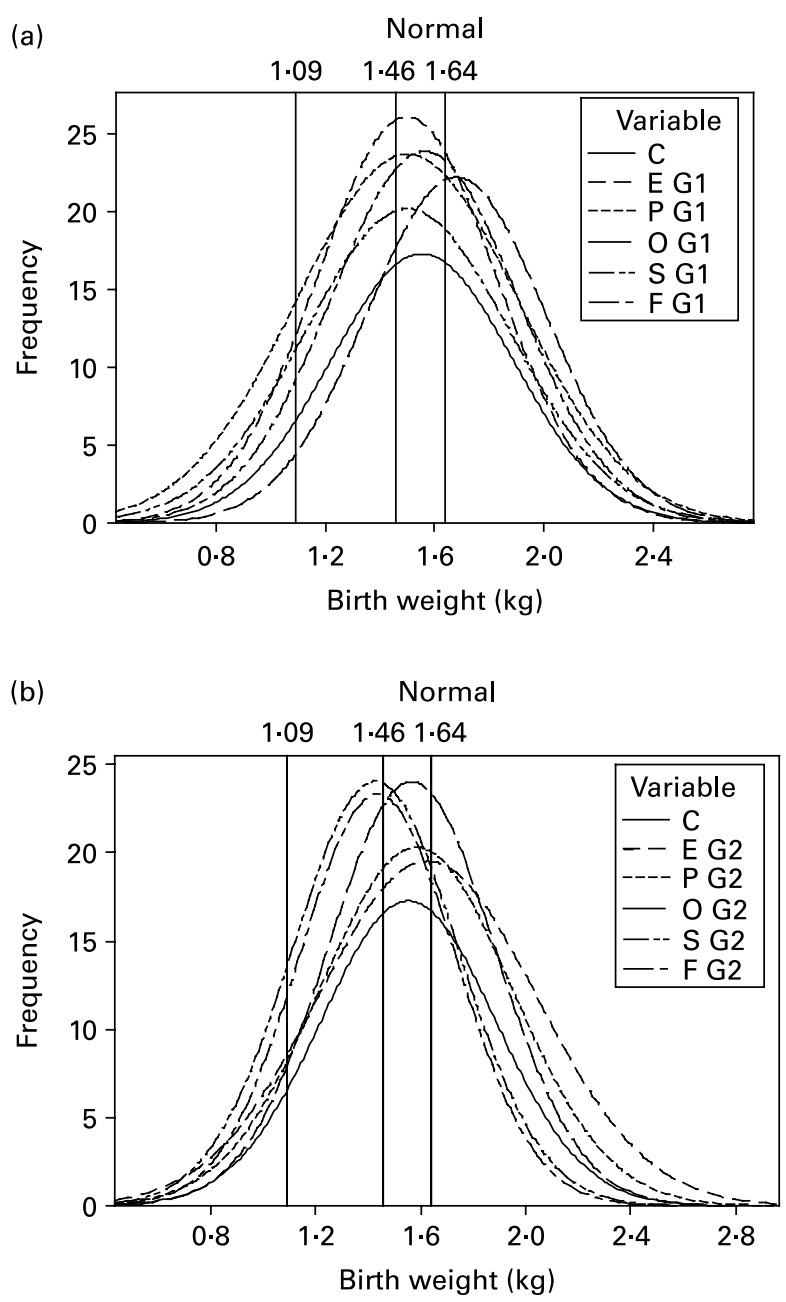

Fig. 2. Effect of type of maternal energy supplement on the distribution of piglet birth weights when supplementation occurs during (a) the first $60 \mathrm{~d}$ of gestation (G1) or (b) from $60 \mathrm{~d}$ of gestation until term (approximately $115 \mathrm{~d}$ ) (G2). C, control; E, excess; P, palm oil; O, olive oil; S, sunflower oil; F, fish oil. For details of diets and procedures, see Methods. 
Table 3. Effect of timing and type of maternal supplement and piglet birth weight category on weight change during the first $21 \mathrm{~d}$ of life ${ }^{\star} \dagger$ (Least squares means with their standard errors)

\begin{tabular}{|c|c|c|c|c|c|c|c|c|c|c|c|c|c|}
\hline & & \multicolumn{4}{|c|}{ Birth weight (kg) } & \multicolumn{4}{|c|}{ Weight at $21 \mathrm{~d}$ of age $(\mathrm{kg})$} & \multicolumn{4}{|c|}{ Neonatal growth rate $(\mathrm{kg} / \mathrm{d})$} \\
\hline & & \multicolumn{2}{|c|}{ LBW } & \multicolumn{2}{|c|}{ NBW } & \multicolumn{2}{|c|}{ LBW } & \multicolumn{2}{|c|}{ NBW } & \multicolumn{2}{|c|}{ LBW } & \multicolumn{2}{|c|}{ NBW } \\
\hline & Con & $0.93^{a}$ & 0.05 & $1 \cdot 61^{a}$ & 0.02 & $5 \cdot 76$ & 0.56 & $7 \cdot 17$ & 0.24 & 0.21 & 0.03 & 0.25 & 0.02 \\
\hline \multirow[t]{4}{*}{$\mathrm{G} 1(0-60 \mathrm{~d})$} & E & $0.94^{a}$ & 0.04 & $1.65^{a}$ & 0.02 & $4 \cdot 61^{b}$ & 0.51 & $7 \cdot 28^{b}$ & 0.20 & 0.16 & 0.03 & 0.24 & 0.02 \\
\hline & $\mathrm{PO}$ & $0.92^{\mathrm{a}}$ & 0.03 & $1.62^{\mathrm{a}}$ & 0.02 & 5.56 & 0.04 & 5.56 & 0.36 & 0.21 & 0.03 & 0.23 & 0.02 \\
\hline & SO & $0.97^{\mathrm{a}}$ & 0.03 & $1.65^{\mathrm{a}}$ & 0.02 & 5.44 & 0.35 & 5.44 & 0.35 & $0 \cdot 19$ & 0.02 & 0.24 & 0.02 \\
\hline & FO & $0.95^{a}$ & 0.03 & $1.63^{a}$ & 0.02 & $5 \cdot 13^{b}$ & 0.47 & $7 \cdot 85^{\mathrm{Ab}}$ & 0.21 & 0.21 & 0.03 & 0.28 & 0.02 \\
\hline \multirow[t]{5}{*}{ G2 (60 d-term) } & $E$ & $0.96^{a}$ & 0.04 & $1.62^{\mathrm{a}}$ & 0.02 & $5 \cdot 23^{b}$ & 0.50 & $7 \cdot 70^{\mathrm{Bb}}$ & 0.22 & $0.20^{c}$ & 0.03 & $0.27^{c}$ & 0.02 \\
\hline & $\mathrm{PO}$ & $0.98^{a}$ & 0.04 & $1.64^{a}$ & 0.02 & $5 \cdot 83$ & 0.51 & $7 \cdot 25$ & 0.20 & $0 \cdot 18^{c}$ & 0.03 & $0.27^{c}$ & 0.02 \\
\hline & $\mathrm{OO}$ & $0.94^{a}$ & 0.03 & $1 \cdot 61^{a}$ & 0.02 & 5.91 & 0.51 & $7 \cdot 26$ & 0.21 & 0.22 & 0.02 & 0.27 & 0.02 \\
\hline & SO & $0.94^{a}$ & 0.03 & $1 \cdot 62^{a}$ & 0.02 & $5 \cdot 19^{b}$ & 0.34 & $5 \cdot 78^{\mathrm{ABb}}$ & 0.22 & $0.20^{c}$ & 0.02 & $0.25^{c}$ & 0.02 \\
\hline & FO & $0.90^{\mathrm{a}}$ & 0.04 & $1 \cdot 67^{\mathrm{a}}$ & 0.02 & $5 \cdot 02^{b}$ & 0.51 & $6 \cdot 94^{\mathrm{b}}$ & $0 \cdot 19$ & 0.17 & 0.03 & 0.23 & 0.02 \\
\hline
\end{tabular}

LBW, low birth weight; NBW, normal birth weight; G1, first half of gestation; G2, second half of gestation; Con, control; E, excess; PO, palm oil; OO, olive oil; SO, sunflower oil; FO, fish oil.

${ }^{a b c}$ Mean values within a row with unlike superscript letters were significantly different $(P<0.05)$.

${ }^{A B}$ Mean values within a column with unlike superscript letters were significantly different $(P<0.05)$

* Data were analysed in Minitab using ANOVA general linear model (parity $(P<0.001)$, sex and litter size $(P<0.001)$ were analysed as covariates).

†For details of diets and procedures, see Methods.

After correction for maternal parity and litter size, growth rate in terms of weight gain per d was similar for all LBW piglets, irrespective of type and timing of maternal supplementation. When the growth rates of low and NBW piglets are compared within treatment groups, less of a difference was apparent when maternal supplementation occurred during G1 (Table 3). This was particularly noticeable when the timing of maternal supplementation with the $\mathrm{E}, \mathrm{PO}$ or $\mathrm{SO}$ diets were compared; the difference between the growth rates of LBW and NBW piglets reached significance only when supplementation occurred during G2 $(P<0 \cdot 05$; Table 3$)$.
After correction for maternal parity and litter size, the LBW offspring of control sows had a greater FFM/kg at birth when compared with either the LBW offspring of supplemented animals or to their NBW siblings $(P<0.01$; Table 4$)$. Interestingly, the LBW offspring of control sows exhibited a more rapid decline in $\mathrm{FFM} / \mathrm{kg}$ over the pre-weaning period than those of supplemented sows $(P<0.05)$ and of their NBW siblings $(P<0.001$; Table 4$)$.

The average daily milk intake of LBW piglets was lower throughout the pre-weaning period than that for their NBW siblings (Table 5). Differences between birth weight groups

Table 4. Effect of timing and type of maternal supplement and piglet birth weight category on change in fat free mass (FFM) per kg body weight, during the first $21 \mathrm{~d}$ of life ${ }^{\star} \dagger$

(Least squares means with their standard errors)

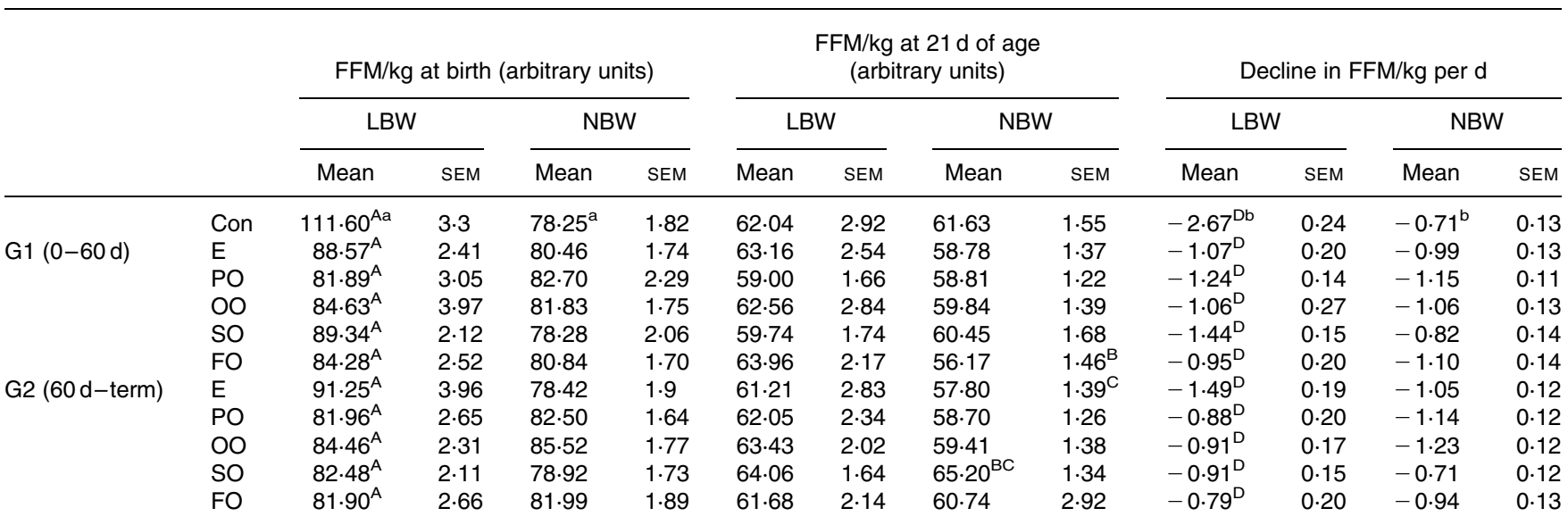

G1, first half of gestation; G2, second half of gestation; LBW, low birth weight; NBW, normal birth weight; Con, control; E, excess; PO, palm oil; OO, olive oil; SO, sunflower oil; FO, fish oil.

${ }^{\mathrm{ab}}$ Mean values within a row with unlike superscript letters were significantly different $(P<0.05)$.

${ }_{A B C D}$ Mean values within a column with unlike superscript letters were significantly different $(P<0.05)$

* Data were analysed in Minitab using ANOVA general linear model (parity, sex and litter size $(P<0.001)$ were analysed as covariates).

†For details of diets and procedures, see Methods. 
Table 5. Effect of timing and type of maternal supplement and piglet birth weight category on milk intake ${ }^{\star} \dagger$ (Least squares means with their standard errors)

\begin{tabular}{|c|c|c|c|c|c|c|c|c|c|}
\hline & & \multicolumn{4}{|c|}{ Milk intake $(\mathrm{kg})$ day 3} & \multicolumn{4}{|c|}{ Milk intake $(\mathrm{kg})$ day 21} \\
\hline & & \multicolumn{2}{|c|}{ LBW } & \multicolumn{2}{|c|}{ NBW } & \multicolumn{2}{|c|}{ LBW } & \multicolumn{2}{|c|}{ NBW } \\
\hline & & Mean & SEM & Mean & SEM & Mean & SEM & Mean & SEM \\
\hline & Con & 0.20 & $0 \cdot 18$ & 0.51 & 0.06 & $0 \cdot 81$ & 0.47 & $1 \cdot 11$ & 0.08 \\
\hline \multirow[t]{5}{*}{ G1 $(0-60 d)$} & E & 0.39 & $0 \cdot 13$ & 0.56 & 0.05 & $0 \cdot 81$ & $0 \cdot 21$ & $1 \cdot 34$ & 0.08 \\
\hline & $\mathrm{PO}$ & 0.34 & 0.12 & 0.52 & 0.07 & 0.88 & 0.24 & 1.34 & 0.12 \\
\hline & O० & 0.53 & $0 \cdot 12$ & $0 \cdot 76$ & 0.05 & $1 \cdot 32$ & $0 \cdot 19$ & $1 \cdot 20$ & 0.09 \\
\hline & SO & 0.35 & $0 \cdot 10$ & 0.51 & 0.05 & $1 \cdot 21$ & $0 \cdot 17$ & 1.02 & 0.07 \\
\hline & FO & 0.51 & $0 \cdot 12$ & 0.57 & 0.05 & $0 \cdot 86$ & $0 \cdot 19$ & $1 \cdot 41$ & 0.08 \\
\hline \multirow[t]{5}{*}{ G2 (60 d-term) } & $E$ & 0.38 & $0 \cdot 14$ & 0.63 & 0.06 & $1 \cdot 24$ & $0 \cdot 21$ & $1 \cdot 36$ & 0.09 \\
\hline & $\mathrm{PO}$ & 0.38 & 0.14 & 0.45 & 0.05 & 1.42 & 0.23 & $1 \cdot 32$ & 0.09 \\
\hline & OO & 0.49 & 0.09 & 0.70 & 0.06 & $1 \cdot 10$ & 0.14 & 1.22 & 0.08 \\
\hline & SO & 0.53 & 0.08 & 0.55 & 0.05 & $1 \cdot 15$ & 0.13 & 1.20 & 0.08 \\
\hline & FO & 0.44 & 0.11 & 0.60 & 0.06 & 0.91 & 0.18 & $1 \cdot 21$ & 0.09 \\
\hline
\end{tabular}

LBW, low birth weight; NBW, normal birth weight; G1, first half of gestation; G2, second half of gestation; Con, control; E, excess; PO, palm oil; OO, olive oil; SO, sunflower oil; FO, fish oil.

${ }^{*}$ Calculated from average individual piglet milk consumption (over four nursings) multiplied by number of suckling per d. Data were analysed in Minitab using ANOVA general linear model (parity $(P<0.01)$, sex and litter size $(P<0.001)$ were analysed as covariates).

†For details of diets and procedures, see Methods.

did not reach significance, however, due to the wide variation in milk intake between LBW piglets.

At commercial end-point (determined by weight), there were no significant differences in pig age, weight or body composition irrespective of birth weight category or maternal diet. Similarly, there was no difference in pig growth rate from birth to slaughter (Table 6).

There was a trend $((P<0 \cdot 1)$ for plasma glucose concentration to be lower on day 3 of life in LBW piglets $(6 \cdot 1$ (SE $0 \cdot 55) \mathrm{mM}$ ) born to EG1 sows compared with their NBW counterparts $(7.69(\mathrm{SE} 0.56) \mathrm{mM})$ but there were no other noticeable differences observed between either birth weight or dietary treatment groups at days 3 and 21 of age. Plasma glucose concentrations tended to be higher on day 3 in those offspring in the $\mathrm{G} 2$ group $(P<0.05)$ compared with $\mathrm{G} 1$ piglets. In G2, LBW piglets $(6.12(\mathrm{SE} 0.66) \mathrm{mm})$ born to SO diet sows had lower plasma glucose $(P<0.05)$ than their NBW siblings (8.12 (SE 0.52)) and LBW animals in the other groups on both days 3 and 21 of postnatal life.

On day 3 of age, plasma TAG and NEFA were higher $(P<0.001)$ in low (TAG 2.96 (SE 0.32) mM; NEFA 3.04 (SE 0.19) $\mathrm{mM}$ ) compared with normal (TAG 1.69 (SE 0.21) mM; NEFA 0.90 (SE 0.11) mM) birth weight piglets born to PO-supplemented sows in G1 and all other treatment groups. These differences were no longer apparent by day 21 as concentrations had decreased $(P<0.001)$ over the neonatal period. Plasma TAG and NEFA were generally higher in LBW offspring born in G1 compared with $\mathrm{G} 2(P<0 \cdot 01)$ on day 3 but this observation was less marked with regard to the NBW group.

NBW (18.15 (SE 2.05) $\mu \mathrm{IU} / \mathrm{ml})$ piglets born to EO sows exhibited elevated $(P<0.001)$ concentrations of plasma insulin compared with their LBW siblings (8.42 (SE 2.29) $\mu \mathrm{IU} / \mathrm{ml}$ ) and all other treatment groups; these differences were not apparent by day 21 of age. LBW FO animals (1.25 (SE 0.22) $\mu \mathrm{IU} / \mathrm{ml})$ had significantly higher $(P<0.05)$ circulating insulin compared with NBW piglets $(0.87(\operatorname{SE~} 0.14) \mu \mathrm{IU} / \mathrm{ml})$ and those born to other fat-supplemented mothers in $\mathrm{G} 2(P<0.001)$ but by day 21 plasma insulin was similar between groups. There was no effect of type or timing of maternal dietary supplementation in gestation or birth weight group on plasma leptin, IGF-1, thyroxine or triiodothyronine at any sampling point.

\section{Discussion}

It is well established that supplementation of the maternal diet during late gestation improves the growth performance and survival of LBW piglets ${ }^{(14-17)}$. This is particularly true with the addition of medium-chain TAG to the sow $\operatorname{diet}^{(18,29)}$. Furthermore Bee ${ }^{(30)}$ found that maternal energy consumption during early gestation determined the ratio of primary to secondary muscle fibres, while birth weight affected muscle fibre area. Both the ratio of primary to secondary muscle fibres and muscle fibre area are known to have consequences for growth performance and carcass composition ${ }^{(31-33)}$. In the present study, both the timing and type of energy supplementation were found to be of importance, with regard to the incidence of LBW piglets, although the body composition of LBW piglets appeared to be improved irrespective of the type or timing of energy supplementation.

The greatest incidence of LBW piglets was observed in the litters of SOG1 sows, in contrast with those of OOG1 animals, which appeared to have a reduced incidence of LBW piglets. The differences observed between these two supplements are likely to have been due to the fatty acid profile of the diet, since parity, total litter size, number of piglets born alive and gestation length were similar for both groups ${ }^{(34)}$. A possible explanation for the differences observed is that gestational gain in back fat thickness at the $\mathrm{P} 2$ position was greater in the SOG1 animals, than in OOG1 sows ${ }^{(34)}$. This suggests that a greater proportion of the supplement was partitioned towards maternal reserves rather than to the growth of the products of conception in SOG1 sows. During the first half of gestation, energy directed towards growth of the products of conception could be expected to improve placental development ${ }^{(24)}$ and may provide an explanation for the decreased occurrence of LBW piglets in the litters of OOG1 animals. It is known 


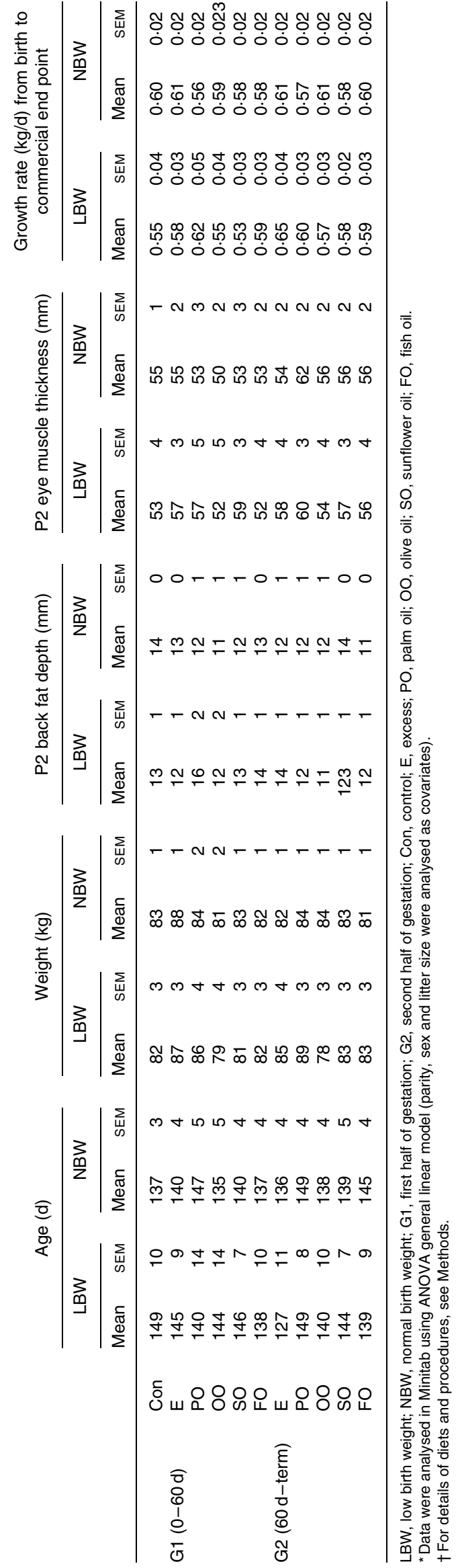

that fetal growth is directly dependent on the supply of nutrients across the placenta and will therefore be influenced by placental development ${ }^{(35,36)}$ and efficiency ${ }^{(37)}$. Analysis of distribution curves of piglet birth weights for the different treatment groups revealed that the mean birth weight of OOG1 piglets is increased. Standard deviation from the mean was similar for OOG1 to that calculated for other supplements, suggesting that more nutrients were available in utero to the offspring of OOG1 sows. It is speculated that improved nutrient availability may be as a result of improved placental development during G1.

It is well established that the growth of small piglets during the pre-weaning period may be improved as a consequence of fat supplementation of their dams ${ }^{(17)}$, suggesting that they can compete more successfully with their litter mates. In the present series of experiments, the growth rate of LBW piglets was similar, irrespective of type or timing of maternal energy supplementation. This is surprising since the average growth rate, from whole litter data, was influenced by the type of maternal energy supplement during $\mathrm{G} 1^{(21,38)}$. It is speculated that the low numbers of LBW piglets, compared with those available from the whole litter, together with other factors affecting piglet growth (litter size, thermal stress, etc.) may have masked the effects of maternal supplementation.

The growth of LBW piglets is known to be slower than that of heavier piglets from the same litter ${ }^{(39-41)}$. In the current experiments comparison of growth rates of LBW and NBW piglets within treatment groups revealed less of a difference in growth rate in the offspring of sows supplemented with extra energy during G1; this is interesting because placental development occurs during the first $60 \mathrm{~d}$ of gestation ${ }^{(24)}$. It is probable that the reduced growth performance of LBW piglets, born to sows supplemented during $\mathrm{G} 2$, may be primarily due to compromised fetal development as a result of placental insufficiency. Other studies have also linked reduced fetal growth to placental insufficiency ${ }^{(22,37,42)}$. The increased weight at $21 \mathrm{~d}$ of age of the NBW offspring of FOG1 sows agrees with the results for average litter performance ${ }^{(21,38)}$ and is in agreement with the findings of others ${ }^{(12,43,44)}$. It has previously been suggested that the improved performance of piglets born to oil-supplemented dams is as a result of improved piglet vigour at birth ${ }^{(12,45)}$; it is speculated that improved vigour at birth may also be responsible for the improved growth performance of NBW FOG1 piglets in the current study. The increased weight at $21 \mathrm{~d}$ of age of NBW offspring, of EG2 sows, is in agreement with the results for whole litter performance $^{(38)}$ and suggests that the balance of energy to protein in maternal diets is important during the second half of gestation if piglet performance is to be maximized.

Body composition of piglets at birth has been the subject of much previous research, it is well known that body fat and glycogen reserves are increased with the addition of fat to maternal diets ${ }^{(9,10,14,46,47)}$. In the current study, it was observed that the LBW piglets of control sows had reduced body fat (as indicated by their higher FFM per $\mathrm{kg}$ ), compared with their NBW siblings and that the addition of extra energy to the maternal diet resulted in increased body fat of LBW piglets, irrespective of the type or timing of supplementation. The present results may provide an explanation for the increased survival of LBW piglets reported in previous studies with maternal supplementation ${ }^{(8,15,16,46)}$, since nutritional status 
and energy balance during the immediate neonatal period is known to be of importance with regard to survival ${ }^{(47,48)}$.

The LBW offspring of control sows had an increased rate of fat deposition during the pre-weaning period, compared with those of supplemented sows and their NBW siblings. By $21 \mathrm{~d}$ of age, surviving LBW offspring of control sows had a similar quantity of FFM per kg body weight to that exhibited by low and NBW piglets in other groups; their body weight was also similar to that for LBW piglets from other treatment groups. Rapid fat deposition also suggests that growth was less efficient than in either NBW siblings or LBW offspring from other groups $^{(33,39)}$. Since the weight gain of all LBW piglets was similar during the first $21 \mathrm{~d}$ of life, but the fat deposition of those born to control sows was greater, their energy intake would be expected to be greater over this period. In the current study, milk energy yield per $\mathrm{kg}$ was similar throughout lactation irrespective of type or timing of maternal energy supplementation $^{(34)}$. Similarly, the milk consumption of LBW piglets was similar irrespective of type or timing of energy supplementation, although there was more variation in milk consumption of control animals than those in other groups. An alternative explanation for the rapid fat deposition observed in LBW offspring of control sows is that they may have consumed more creep feed than those from other groups, although this seems unlikely since the consumption of creep feed during the first 3 weeks of life is usually very low ${ }^{(49)}$.

Previously, LBW piglets have been observed to reach a lower mature body weight, when compared with heavier litter mates ${ }^{(40)}$. Consequently, there is an inverse relationship between birth weight and time taken to reach commercial slaughter weight ${ }^{(41)}$. Similarly, average daily gain has been observed to be lower in LBW pigs prior to weaning and from weaning to $70 \mathrm{~d}$ of age ${ }^{(32)}$. In the present study, there was no significant difference in age of pigs at slaughter, irrespective of timing or type of maternal supplementation or piglet birth weight. Although not significant, age at slaughter was generally slightly higher for LBW animals, but the reverse was true in the case of those animals whose dams had received EG2, FOG2 or POG1 diets; it is not clear whether these results demonstrate improved performance of some LBW piglets as a result of catch-up growth ${ }^{(50)}$.

Previously it has been found that LBW piglets have lower feed conversion efficiency, due to their lower potential for lean deposition, compared with NBW pigs ${ }^{(32,39)}$. In the current studies, no difference was observed in the back fat depth or eye muscle thickness at the $\mathrm{P} 2$ position at slaughter. This is in agreement with the findings of England ${ }^{(51)}$ and Hegarty \& Allen ${ }^{(52)}$, who found no difference in the carcass composition of low and NBW animals at similar slaughter weights. Recently, it has been suggested that the feed conversion efficiency of small pigs $(0.9-1.3 \mathrm{~kg})$ is similar to that observed for larger pigs, but that very small pigs $(800-900 \mathrm{~g})$ have a $30 \%$ lower feed conversion efficiency ${ }^{(41)}$; this has previously been hinted at by Powell \& Aberle ${ }^{(39)}$. In the present study, average birth weight of LBW piglets was above $0.9 \mathrm{~kg}$, irrespective of maternal diet, and may provide an explanation for the lack of difference observed between birth weight groups.

In addition to those already discussed, there are a number of other factors that were not measured that influence pig growth. It is well established that social stressors influence pig performance ${ }^{(53-55)}$. On the College Unit, piglets are grouped by sex and weight at weaning into pens of thirty animals. By dividing pigs into groups in this way, it becomes possible for a LBW pig to become more dominant than would be possible if whole litters were transferred together. Similarly, a dominant animal, which gets grouped with the largest pigs weaned, may end up in a subordinate position. It is not well documented as to how such social situations would affect the feed consumption and efficiency of thermoregulation and growth in pigs from different birth weight groups.

A previous study by Boyd et al. ${ }^{(10)}$ demonstrated that the addition of fat to the maternal diet did not influence piglet plasma glucose at birth. However, other studies have reported that the addition of medium-chain TAG or saturated fat to the sows' diet during late gestation cause an increase in glucose concentration of up to $16 \%^{(14,18)}$. The present data support these findings and are further modified by the timing of maternal supplementation as plasma glucose was higher in G1 compared with G2 offspring. Moreover, this mirrors the differences in maternal glucose towards the end of pregnancy. It is proposed that exposure to high concentrations of glucose in utero (as a cause of glucose-sparing) alters the hypothalamic set-point of the offspring and thus they strive to maintain this elevated set-point after birth. By day 21 the differences in plasma glucose are no longer apparent, suggesting that the glucose set-point may be readjusted as the offspring adapts to postnatal life.

Several studies have reported that fat in the late gestation diet of sows has no effect on piglet plasma $\operatorname{NEFA}^{(10,56,57)}$ and $\mathrm{TAG}^{(56)}$ concentration. With the exception of the POG1 offspring, a similar scenario was demonstrated in the current investigation. The reasons why pigs born to POG1 sows exhibited elevated concentrations of NEFA and TAG remains to be fully established.

NBW piglets born to either G1 or G2 sows exhibited higher concentrations than their LBW counterparts and all offspring born to fat-supplemented mothers. The higher concentrations of insulin on day 3 of age may also provide one explanation for the lower plasma glucose observed in these pigs. There is great variation in the insulin results obtained in the current study, which may be due to the inability to starve the pigs prior to blood sampling as they had access to feed ad libitum. Insulin concentrations are usually low before a feed and much higher after an intake of food. Since blood samples were not necessarily taken from the pigs at the same time interval after feeding, there will be a high degree of variation in the results. It is interesting to note that there was no difference in maternal plasma glucose between EG1 and EG2, which may in part explain why insulin concentrations are similar in these groups.

It is well documented that IGF-1 is an important regulator of postnatal growth and development and so, as expected, overall plasma IGF-1 concentrations were shown to increase from day 3 to day 21. Averette et al. ${ }^{(58)}$ has previously shown that IGF-1 is higher in the colostrums of sows fed fat and these authors proposed that this may be one explanation for the improved neonatal growth rate of their piglets. There is no evidence to support this hypothesis in the present study as differences in IGF-1 were not apparent, despite differences in growth between LBW and NBW piglets.

Thyroid hormones are known to influence both the physical and behavioural development of the newborn animal. Low plasma 
concentrations of thyroxine and triiodothyronine have been linked to LBW and poor growth performance in sheep ${ }^{(59)}$ but a similar situation was not observed in the present study.

\section{Conclusions}

Maternal dietary supplementation altered the distribution of piglet birth weights and improved the energy status of LBW piglets, irrespective of the fatty acid profile or timing of the supplement. Supplementation with MUFA during G1 appeared to have beneficial effects as it reduced the incidence of LBW, whereas offering a diet high in PUFA had the reverse effect.

\section{Acknowledgements}

The authors wish to acknowledge the financial support of the Commission of the European Communities (QLK1-200100138 ). PERILIP; this grant was awarded to P. F. D., L. C. and I. J. L. This work does not necessarily reflect the views of the Commission and in no way anticipates its future policy in this area. The authors thank United Fish Industries for providing the salmon oil and the staff at The Pig Research and Development Unit for their care of animals throughout the study. The authors would also like to thank Emilio Herrera and Encarnacion Amusquivar (Universidad San Pablo-CEU, Madrid, Spain) for analysing the fatty acid profile of the experimental diets. The technical help of Kate Perkins and Kirsty Massey was also greatly appreciated. The investigation team are former members of the Animal Science Research Section of Imperial College London (Wye Campus). There are no conflicts of interest.

\section{References}

1. MLC (2003) MLC Pig Yearbook. Milton-Keynes: MLC.

2. Dyke GW \& Swierstra EE (1987) Causes of piglet death from birth to weaning. Can J Anim Sci 67, 543-547.

3. Van der Lende T, Knol EF \& Leenhouwers JI (2001) Prenatal development as a predisposing factor for perinatal losses in pigs. Reprod Suppl 58, 247-261.

4. Varley MA (1995) Introduction. In The Neonatal Pig, Development and Survival, pp. 1-16 [MA Varley, editor]. Oxford, UK: CAB International.

5. Pettigrew JE Jr (1981) Supplemental dietary fat for peripartal sows: a review. J Anim Sci 53, 107-117.

6. Lean IJ (1999) Pigs. In Management and Welfare of Farm Animals, 4th ed., pp. 137-166, [R Ewbank, F Kim-Madslien and CB Hart, editors]. Wheathampstead, Herts: UFAW.

7. Herpin P, Damon M \& Le Dividich J (2002) Development of thermoregulation and neonatal survival in pigs. Livest Prod Sci 78, 25-45.

8. Boyd RD, Moser BD, Peo ER Jr \& Cunningham PJ (1978) Effect of energy source prior to parturition and during lactation on piglet survival and growth and on milk lipids. J Anim Sci 47, $883-892$.

9. Boyd RD, Moser BD, Peo ER Jr \& Cunningham PJ (1978) Effect of energy source prior to parturition and during lactation on tissue lipid, liver glycogen and plasma levels of some metabolites in the newborn pig. J Anim Sci 47, 875-882.

10. Boyd RD, Moser BD, Lewis AJ, Peo ER Jr, Johnson RK \& Nimmo RD (1981) Effect of maternal dietary energy source on glucose homeostasis, liver glycogen and carcass lipid in the neonatal pig. J Anim Sci 53, 1316-1324.

11. Wladyslaw M (1991) Chemical composition of colostrum and milk in sows fed diets supplemented with animal fat. Rev Anim Prod 26, 11-15.

12. Rooke JA, Sinclair AG, Edwards SA, Cordoba R, Pkiyach S, Penny PC, Penny P, Finch AM \& Horgan GW (2001) The effect of feeding salmon oil to sows throughout pregnancy on pre-weaning mortality of piglets. Anim Sci 73, 489-500.

13. Averette Gatlin L, Odle J, Soede J \& Hansen JA (2002) Dietary medium- or long-chain triglycerides improve body condition of lean genotype sows and increase suckling pig growth. J Anim Sci 80, 38-44.

14. Seerley RW (1989) Survival and postweaning performance of pigs from sows fed fat during late gestation and lactation. J Anim Sci 67, 1889-1894.

15. Cast WR, Moser BD, Peo ER Jr \& Cunningham PJ (1977) Fat, Choline and thyroprotein additions to the diet of lactating swine. J Anim Sci 45, Suppl. 1, 80 (Abstract).

16. Cieslak DG, Leibbrandt VD \& Benevenga NJ (1983) Effect of a high fat supplement in late gestation and lactation on piglet survival and performance. J Anim Sci 57, 954-959.

17. Cox NM, Britt JH, Armstrong WD \& Alhusen HD (1983) Effect of feeding fat and altering weaning schedule on rebreeding in primiparous sows. J Anim Sci 56, 21-29.

18. Jean K \& Chiang S (1999) Increased survival of neonatal pigs by supplementing medium-chain triglycerides in late gestating sow diets. Anim Feed Sci Tech 76, 241-250.

19. Barker DJ (1995) Fetal origins of coronary heart disease. BMJ 311, $171-174$.

20. Eriksson JG (2005) The foetal origins hypothesis - 10 years on. BMJ 330, 1096-1097.

21. Laws J, Laws A, Lean IJ, Dodds PF \& Clarke L (2007) Growth and development of offspring following supplementation of sow diets with oil during early to mid gestation. Animal 1, 1482-1489.

22. Ashworth CJ \& McArdle HJ (1999) Both placental amino acid uptake and fetal plasma amino acid concentrations differ between small and normally-grown porcine fetuses. Early Hum Dev 54, 90-91 (Abstract).

23. Pomeroy RW (1960) Infertility and neonatal mortality in the sow. III. Neonatal mortality and foetal development. J Agric Sci 54, 31-57.

24. Knight JW, Bazer FW, Thatcher WW, Franke DE \& Wallace HD (1977) Conceptus development in intact and unilaterally hysterectomized-ovariectomized gilts: interrelations among hormonal status, placental development, foetal fluids and foetal growth. J Anim Sci 44, 620-637.

25. DEFRA (2003) Code of Recommendations for the Welfare of Livestock. http://www.defra.gov.uk/animalh/welfare/farmed/ pigs/pigcode.pdf (accessed 14 February 2005).

26. Sinclair AG, Shaw JM, Edwards SA, Hoste S \& McCartney A (1999) The effect of dietary protein level on milk yield and composition and piglet growth and composition of the Meishan synthetic and European White breeds of sow. Anim Sci 68, 701-708.

27. Klaver J, van Kempen GJM, de Lange PGB, Verstegen MWA \& Boer H (1981) Milk components and daily yield of different milk components as affected by sow condition and lactation/ feeding regimen. J Anim Sci 52, 1091-1097.

28. Noblet J \& Etienne M (1986) Effect of energy level in lactating sows on yield and composition of milk and nutrient balance of piglets. J Anim Sci 63, 1888-1896.

29. Azain MJ (1993) Effects of adding medium-chain triglycerides to sow diets during late gestation and early lactation on litter performance. J Anim Sci 71, 3011-3019.

30. Bee G (2004) Effect of early gestation feeding, birth weight, and gender of progeny on muscle fibre characteristics of pigs at slaughter. J Anim Sci 82, 826-836. 
31. Powell SE \& Aberle ED (1981) Skeletal muscle and adipose tissue cellularity in runt and normal birth weight swine. $J$ Anim Sci 52, 748-756.

32. Dwyer CM, Fletcher JM \& Stickland NC (1993) Muscle cellularity and postnatal growth in the pig. J Anim Sci 71, 3339-3343.

33. Dwyer CM, Stickland NC \& Fletcher JM (1994) The influence of maternal nutrition on muscle fibre number development in the porcine fetus and on subsequent postnatal growth. $J$ Anim Sci 72, 911-917.

34. Laws J, Amusquivar E, Laws A, Herrera E, Lean IJ, Dodds PF \& Clarke L (2008) Supplementation of sow diets with oil during gestation: sow body condition, milk yield and milk composition. Livest Sci, In the press.

35. Hammond $\mathrm{J}$ (1914) On some factors controlling fertility in domestic animals. J Agric Sci 6, 263-277.

36. Hammond J (1921) Further observations on the factors controlling fertility and foetal atrophy. J Agric Sci 11, 337-366.

37. Ashworth CJ, Finch AM, Page KR, Nwagwu MO \& McArdle HJ (2001) Causes and consequences of foetal growth retardation in pigs. Reprod Suppl 58, 233-246.

38. Laws J, Laws A, Lean IJ, Dodds PF \& Clarke L (2007) Growth and development of offspring following supplementation of sow diets with oil during mid to late gestation. Animal 1, 1490-1496.

39. Powell SE \& Aberle ED (1980) Effects of birth weight on growth and carcass composition of swine. J Anim Sci 50, 860-868.

40. Ritacco B, Radecki SV \& Schoknecht PA (1997) Compensatory growth in runt pigs is not mediated by insulin-like growth factor I. J Anim Sci 75, 1237-1243.

41. Gadd J (2003) Pig Production Problems, pp. 19-26. Nottingham: Nottingham University Press.

42. Warshaw JB (1990) Nutritional correlates of fetal growth. Dev Pharm Therap 15, 153-158.

43. Rooke JA, Shanks M \& Edwards SA (2000) Effect of offering maize, linseed or tuna oils throughout pregnancy and lactation on sow and piglet tissue composition and piglet performance. Anim Sci 71, 289-299.

44. Rooke JA, Sinclair AG \& Edwards SA (2001) Feeding tuna oil to the sow at different times during pregnancy has different effects on piglet long-chain polyunsaturated fatty acid composition at birth and subsequent growth. Br J Nutr 86, 21-30.

45. Cordoba R, Pkiyach S, Rooke JA, Edwards SA, Penny PC \& Pike I (2000) The effect of feeding salmon oil during pregnancy on causes of piglet deaths prior to weaning. Proc Br Soc Anim Sci, 105 (Abstract).
46. Seerley RW, Pace TA, Foley CW \& Scarth RD (1974) Effect of energy intake prior to parturition on milk lipids and survival rate, thermostability and carcass composition of piglets. $J$ Anim Sci 38, 64-70.

47. Le Dividich J, Esnault T, Lynch B, Hoo-Paris R, Castex C \& Peiniau J (1991) Effect of colostral fat level on fat deposition and plasma metabolites in the newborn pig. J Anim Sci 69, $2480-2488$

48. Leenhouwers JI, Knol EF, De Groot PN, Vos H \& Van de Lende T (2002) Fetal development in the pig in relation to genetic merit for piglet survival. J Anim Sci 80, 1759-1770.

49. Pluske JR, Williams IH \& Aherne FX (1995) Nutrition of the neonatal pig. In The Neonatal Pig - Development and Survival, pp. 187-235 [MA Varley, editor]. Oxford, UK: CAB International.

50. Widdowson EM \& McCance RA (1975) A review: new thoughts on growth. Pediatr Res 9, 154-156.

51. England DC (1974) Husbandry components in prenatal and perinatal development in swine. J Anim Sci 38, 1045-1049.

52. Hegarty PVJ \& Allen CE (1978) Effect of pre-natal runting on the post-natal development of skeletal muscles in swine and rats. J Anim Sci 46, 1634-1640.

53. National Research Council (1998) Nutrient Requirements of Swine, 10th revised ed., pp. 1-189. Washington, DC: National Academy Press.

54. Wellock IJ, Emmans GC \& Kyriazakis I (2003) Predicting the consequences of social stressors on pig food intake and performance. J Anim Sci 81, 2995-3007.

55. Schmolke SA, Li YZ \& Gonyou HW (2003) Effect of group size on performance of growing-finishing pigs. J Anim Sci 81, 874-878.

56. Rooke JA, Bland IM \& Edwards SA (1998) Effect of feeding tuna oil or soybean oil as supplements to sows in late pregnancy on piglet tissue composition and viability. $\mathrm{Br} J$ Nutr 80, $273-280$.

57. Newcomb MD, Harmon DL, Nelssen JL, Thulin AJ \& Allee GL (1991) Effect of energy source fed to sows during late gestation on neonatal blood metabolite homeostasis, energy stores and composition. J Anim Sci 69, 230-236.

58. Averette LA, Odle J, Monaco MH \& Donovan SM (1999) Dietary fat during pregnancy and lactation increases milk fat and insulin-like growth factor I concentration and improves neonatal growth rates in swine. J Nutr 129, 2123-2129.

59. Clarke L, Darby CJ, Lomax MA \& Symonds ME (1994) Effect of ambient temperature during 1st day of life on thermoregulation in lambs delivered by caesarean section. J Appl Physiol 76, $1481-1488$. 